\title{
A Case of Bilateral Endobronchial Squamous Cell Carcinoma Mimicking Asthma
}

ANIRBAN SARKAR, ${ }^{1}$ ANIRBAN DAS, ${ }^{2}$ SIBES KUMAR DAS, ${ }^{3}$ SOUMYA DAS, ${ }^{2}$ SABYASACHI CHOUDHURY ${ }^{2}$

\begin{abstract}
:
Partial or complete obstruction of bronchial tree by endobronchial tumours results in obstructive hyperinflation, non - resolving pneumonia, or atelectasis. Partial endobronchial obstruction may be associated with wheezes, which mimic asthmatic attack, non - responding to inhaled medications. Here, we report a rare case of bilateral endobronchial squamous cell carcinoma, presenting with obstructive hyperinflation and wheezes, which was wrongly diagnosed as 'difficult asthma' in a forty - year old male. Histopathology of endobronchial biopsy tissue ultimately revealed the truth.
\end{abstract}

Key words: Partial endobronchial obstruction, Obstructive hyperinflation, Monophonic wheezes, Squamous cell carcinoma, difficult asthma.

\section{Introduction:}

Endobronchial tumors rarely mimic asthma, not improved with inhaled medications and diagnosed as 'difficult asthma'. High index of suspicion and early diagnostic bronchoscopy \& biopsy are needed to avoid the delay in the diagnosis of endobronchial malignancy, and to ensure early surgical intervention. Endobronchial lipoma, leiomyoma, adenoma, mucoepidermoid carcinoma, adenoid cystic carcinoma, and metastatic carcinoma have been found to present with asthma like symptoms. Here we report a rare case of endobronchialsqamous cell carcinoma producing asthma - like symptoms in a 40 year old male.

\section{Case Report:}

A 40 - year old male, smoker patient presented with cough and scanty, mucoid expectoration, exertional shortness of breath and wheeze for one year.The cough was aggravated at night on lying down position. There were three episodes of streaky hemoptysis since last six months. He also complained of progressive breathlessness of insidious onset, associated with wheezes, diurnal variation, and several seasonal exacerbations. History of anorexia and significant weight loss over one year was present. There was no history

1. Associate Professor, Department of Pulmonary Medicine, Midnapore Medical College, PaschimMidnapore, West Bengal, India

2. Assistant Professor, Department of Pulmonary Medicine, Medical College, Kolkata, West Bengal, India

3. Professor, Department of Pulmonary Medicine, Medical College, Kolkata, West Bengal, India

Correspondence : Dr. Anirban Das.Assistant Professor, Department of Pulmonary Medicine, Medical College, Kolkata, West Bengal, India. Phone No: (0)9434672168. E-mail : dranirbandas_chest@rediffmail.com suggestive of atopy, childhood asthma, and GERD. However, the patient was diagnosed as having 'difficult asthma' and advised for inhaled long acting $\beta_{2}$ agonist and inhaled corticosteroid combination and short acting $\beta_{2}$ agonist. Due to lack of symptomatic improvement, at first montelukast, and then sustained - release theophylline were added, but again, no improvement was documented. Different antibiotics are also advised to treat 'exacerbations'. In this stage, he attended our hospital with same symptoms with increased severity.

On general survey, there was anemia, but no clubbing, cyanosis and lymphadenopathy. His temperature was $97^{\circ} \mathrm{F}$, pulse - $110 \mathrm{bpm}$, respiratory rate 24 breaths/minute and BP 110/70 mmHg. He was comfortable on sitting upright position. On examination of respiratory system, there was tachypnoea, intercostal suction and over activity of accessory muscles of respiration. Mediastinum was central. Hyperresonant percussion note was found over second, third and fourth intercostal spaces along left midclavicular line, fourth and fifth intercostal spaces along left midaxilary line and left interscapular area with diminished vesicular breath sound over same areas. Fixed, monophonic, localizedwheezes were audible over right and left infraclavicular areas.

Complete hemogram and blood biochemistry were normal, except increased eosinophil count $(720 / \mathrm{cmm})$. Sputum for AFB was negative. Chest X-ray and electrocardiogram were normal. Spirometry showed obstructive pattern without reversibility with short acting $\beta_{2}$ agonist inhalation. Contrast enhanced CT scan of chest revealed left upper lobe hypertranslucency and intraluminal lesion in right and left main bronchi (Figure- 1). Fiberoptic bronchoscopy revealed 


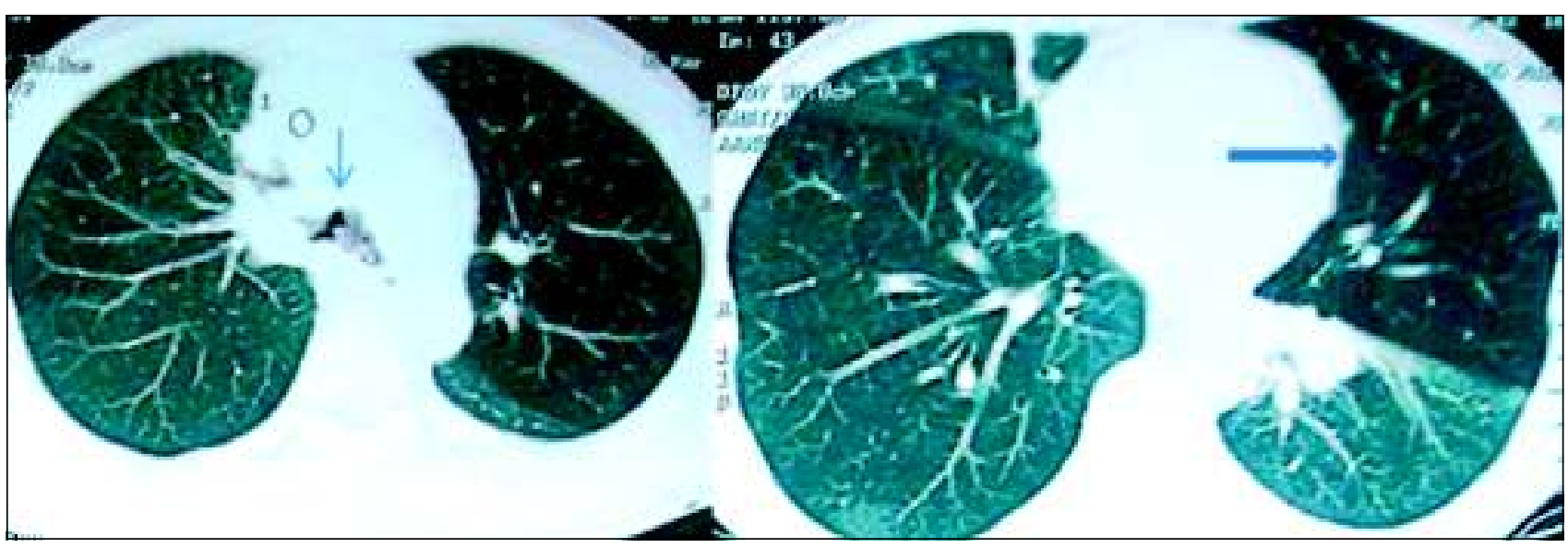

Fig.-1: Contrast enhanced CT scan showing left upper lobe hypertranslucency (bold arrow) and endobronchial lesion (arrow).

widened carina, infiltrated with whitish nodules; a proliferative, nodular growth partially occluding the lumen of left main bronchus and multiple nodules involving right main bronchus, infiltrating distally and partially occluding the opening of right upper lobebronchus (Fig.-2). Endobronchial biopsy was taken from the nodules of both sides and histopathological examination revealed squamous cell carcinoma (Fig.-3). Post - bronchoscopy sputum for malignant cells was negative. USG of whole abdomen, colonoscopy and upper GI endoscopy were within normal limit. Radionuclide bone scan, contrast enhanced CT scan of brain, and whole body CT scan were normal. Hence bilateral endobronchial squamous cell carcinoma was diagnosed, and the patient was advised cytotoxic chemotherapy, but he was lost to follow up.

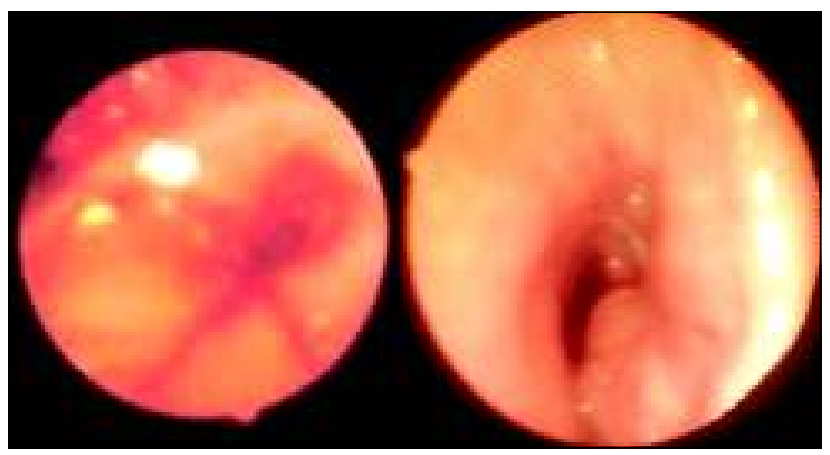

(a)

(b)

Fig.-2: (a) Fiberoptic bronchoscopy showing widened carina, infiltrated with whitish nodules and multiple nodules involving left and right main bronchi. (b) Fiberoptic bronchoscopy showing endobronchial mass lesion in left main bronchus.

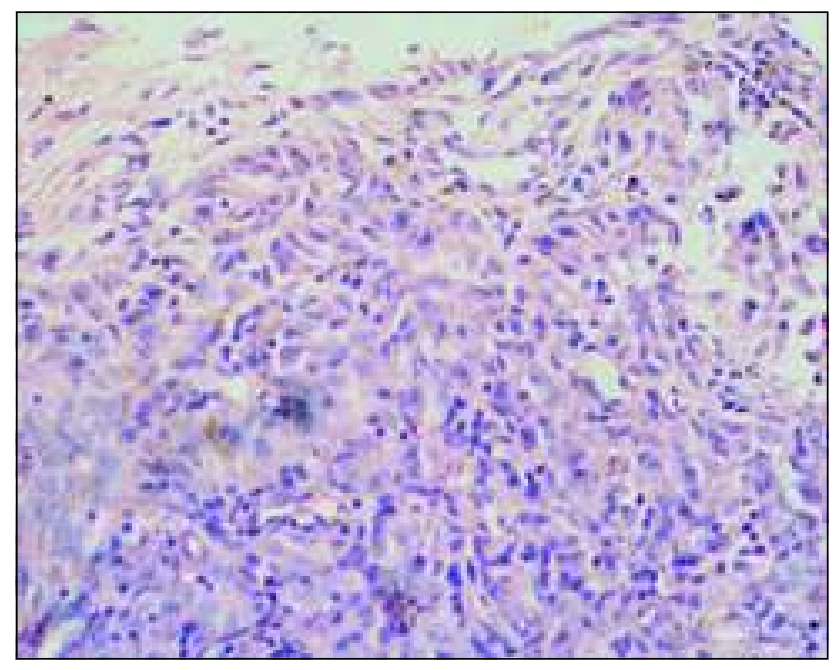

Fig.-3: Photomicrograph of histopathology of endobronchial biopsy showing squamous cell carcinoma (H\&E stain, x400).

\section{Discussion:}

Endobronchialtumours like lipoma, leiomyoma, carcinoid tumour, mucoepidermoid carcinoma, adenoid cystic carcinoma, metastatic carcinoma are reported in the literature to cause partial or complete endobronchial obstruction. ${ }^{1-7}$

Lung cancer is most common malignancy throughout the world and more than $50 \%$ of these tumours involve central airways. ${ }^{8}$ Among centrally placed lung cancers, squamous cell and small cell histopathological subtypes are most common, especially in tobacco smokers. Airway involvement may be due to bulky endobronchial disease, endobronchial extension, or external compression of the airways by tumour itself or by lymphadenopathy. ${ }^{9}$ 
Endobronchialtumour may obstruct central airways partially or completely. Complete obstruction of larger airwaycauses absorption collapse or atelectasis which is easily diagnosed by radiology and bronchoscopic biopsyoften reveals its histopathological diagnosis.

On the other hand, partial obstruction of airway by endobronchial neoplasm may result in recurrent post obstructive pneumonias, or air trapping in the segments distal to the obstruction. Non - resolving pneumonia may be absent as draining of secretions from distal segment is often adequate due to follicular nature of the endobronchial growth, causing incomplete obstruction. But this type of growth may act as 'ball - valve' and air trapping during expiratory phase results in obstructive hyperinflation.

However the patient may also present withdyspnoea, cough, and focal, fixed, monophonic, inspiratory wheezes with absolutely normal chest X-ray. This may simulate obstructive airway disease, especially asthma in young age group, but treatment with inhaled corticosteroid and inhaled long acting $\mathrm{b}_{2}$ agonist does not result in any improvement. On contrast enhanced CT scan of thorax, endobronchial follicular lesion is often missed. Hence fiberoptic bronchoscopy is essential in these cases of 'difficult asthma' for early diagnosis of endobronchial malignancy and early surgical intervention may change the future prognosis.

\section{Conclusion:}

Fixed monophonic wheeze is a characteristic sign of incomplete occlusion of a main stem or lobar bronchus by tumours, foreign body, cicatricial stenosis, or intrabronchial granulomata. The source of wheeze is a jet of air flowing at a high velocity through a narrow chink which sets the endobronchial mass and the adjoining walls of the bronchus into rapid oscillation. This wheeze may be inspiratory, expiratory, or both. The wheeze may disappear when the patient lies down from one side to the other. This is an important sign of obstructive endobronchial lesions.

\section{Conflict of Interest : None}

\section{References:}

1. Basoglu A, Celik B, Akdag AO, Sengul AT. Endobronchial lipoma: A rare cause of bronchial occlusion. Interact CardiovascThoracSurg 2004;3:263 - 64.

2. Özçelik U, Kotiloðlu E, Göçmen A, Penocak M E, Kiper N. Endobronchial leiomyoma: a case report. Thorax 1995; 50: 101-2.

3. Chan AKW, Tan KL, Takano A, Lee P. A middle - aged asthmatic woman with unresolving cough. Chest 2011;139:712-6.

4. Sogut A, Yilmaz O, Yuksel H. A rare cause of persistent atelectasis in childhood: mucoepidermoid carcinoma. Tuberk Toraks 2008;56:325 - 8.

5. Albers E, Lawrie T, Harrell JH, Yi ES. Trachebronchial adenoid cystic carcinoma: a clinicopathologic study of 14 cases. Chest 2004;125:1160-5.

6. Allen LM, Arida MA, Zurbriggen TL, Thompson GP, Manske BR, Berg LC et al. Persistent massive hydropneumothorax in young women with pulmonary adenoid cystic carcinoma : an unusual and rapidly fatal presentation. ClinPulm Med 2011;18:49-51.

7. Amer E, Guy J, Vaze B. Endobronchial metastasis from renal adenocarcinoma simulating a foreign body. Thorax 1981;36:183-4.

8. LuomanenRKJ, Watson WL. Autopsy findings. In: Watson WL, ed. Lung Cancer: A Study of Five Thousand Memorial Hospital Cases. St Louis, Mo: CV Mosby Co: 1968: $504-10$.

9. Simoff MJ. Endobronchial management of advanced lung cancer. Cancer Control 2001;8: 337-43. 